\title{
IMPLEMENTASI ALGORITMA K-MEANS CLUSTERING UNTUK MENENTUKAN KELAS KELOMPOK BIMBINGAN BELAJAR TAMBAHAN (STUDI KASUS : SISWA SMA NEGERI 1 RANAH PESISIR)
}

\author{
Mardalius \\ Program Studi Sistem Informasi, STMIK Royal Kisaran \\ Jl. Prof. M. Yamin 173 Kisran, Sumatera Utara 21222 \\ Email : mardalius@ royal.ac.id
}

\begin{abstract}
Abstrak
Belajar tambahan adalah program belajar yang dilaksanakan di luar program intrakurikuler sekolah. Artinya, kegiatan belajar tambahan dilaksanakan setelah program belajar reguler di sekolah telah berakhir Pembimbing belajar berasal dari guru mata pelajaran di sekolah bersangkutan. Lazim disebut program belajar tambahan sore. Program belajar tambahan sore memiliki skedul perencanaan tersendiri. Belajar tambahan dilakukan oleh siswa bertujuan untuk meningkatkan pemahaman dan pendalaman terhadap materi suatu mata pelajaran. Tujuan ini berkaitan dengan persiapan seorang siswa untuk menghadapi ujian di sekolah, baik ujian tengah semester, ujian akhir semester maupun ujian akhir nasional. Dalam menentukan kelas kelompok belajar tambahan ini menggunakan algoritma K-Means Clustering, jumlah sampel data akan di gunakan adalah sebanyak 26 orang siswa jurusan IPA.
\end{abstract}

Kata kunci : Data Mining, K-Means, Clustering, Kelompok Belajar 


\section{PENDAHULUAN}

SMA Negeri 1 Ranah Pesisir dalam menghadapi Ujian Nasional (UN) akan mengadakan suatu kelompok bimbingan belajar. Hal ini bertujuan untuk memantapkan materi - materi mata pelajaran yang akan di ujikan. Dalam perkembangannya sistem pembagian kelompok bimbingan belajar yang ada saat ini dirasa kurang efektif dikarenakan penekanan pembelajaran yang diberikan untuk semua kelompok (kelas). Sedangkan tingkat kemampuan siswa dalam setiap mata pelajaran tidak sama. Sebagian siswa hanya tanggap dalam beberapa mata pelajaran, dan ada sebagian yang tanggap dalam semua mata pelajaran. Masalah tersebut mengakibatkan kurangnya minat siswa dalam mengikuti proses bimbingan belajar. Belum adanya system pembagian kelompok bimbingan belajar, menyebabkan pembagian kelompok bimbingan belajar tidak sesuai harapan. Permasalahan yang timbul adalah pihak sekolah mengalami kesulitan dalam menentukan kelompok bimbingan dalam menentukan tingkat kemampuan siswa. Ini dikarenakan tiap-tiap siswa mempunyai kemampuan memahami mata pelajaran yang berbeda-beda Pengelompokan siswa pada kelompok yang tepat akan mampu mengimprovisasi hasil pembelajaran menjadi lebih baik (Henry, 2013).

Knowledge discovery in Database (KDD) didefinisikan sebagai ekstraksi informasi potensial, implisit dan tidak dikenal dari sekumpulan data. Proses knowledge discovery melibatkan hasil dari proses data mining (proses mengekstrak kecenderungan pola suatu data), kemudian mengubah hasilnya secara akurat menjadi informasi yang mudah dipahami (Ronald, 2015). Proses knowledge discovery in database (KDD) secara garis besar terdiri dari Data Selection, Preprocessing/Cleaning, Transformation, Data mining, dan Interpretation/Evaluation.

Algoritma K-Means merupakan algoritma non hirarki yang berasal dari metode data clustering, Menurut Eko Prasetyo (2012) mengatakan bahwa metode K-Means ini mempartisi data kedalam kelompok sehingga data berkarakteristik sama dimasukan kedalam sat kelompok yang sama dan data yang berkarakteristik berbeda dikelompokkan kedalam kelompok yang lain. Adapun tujuan dari pengelompokan data ini adalah untuk meminimalkan fungsi objektif yang diset dalam proses pengelompokan, yang pada umumnya berusaha meminimalkan variasi didalam suatu kelompok dan memaksimalkan variasi antar kelompok
Pemilihan metode K-Means dikarenakan metode ini harus menggunakan data fisik tidak abstrak dan bersifat jelas, hal ini sesuai dengan data yang akan digunakan pada permasalahan di dalam pengelompokan bimbingan belajar di SMA Negeri 1 Ranah Pesisir. Selain itu, metode ini bersifat fleksibel sebab pengguna dapat menentukan jumlah cluster yang akan dibuat.

Beberapa penulis terdahulu telah menerapkan teknik $K$-Means Clustering sebagai penelitian dalam hal pengelompokan data, diantaranya :

Wirta Agustin, Erlin (2016) Dalam penelitiannya yang berjudul "Implementasi Metode $K$ Means Cluster Analysis Untuk Memilih Strategi Promosi Penerimaan Mahasiswa Baru". Dalam penelitian ini penulis menjelaskan bahwa metode $K$ Means Clustering dapat membantu dalam pemilihan strategi promosi Penerimaan Mahasiswa Baru pada STMIK Amik Riau.

Sri Tria Siska (2016) dengan penelitiannya yang mengangkat judul "Analisa Dan Penerapan Data Mining Untuk MenentukanKubikasi Air Terjual Berdasarkan Pengelompokan Pelanggan Menggunakan Algoritma K-Means Clustering". Bahwa Metode algoritma $K$-Means Clustering dapat diterapkan pada kubikasi air terjual berdasarkan pengelompokan pelanggan di PDAM Kab.50 Kota, sehingga metode ini sangat membantu pihak PDAM Kab.50 Kota dalam menentukan pelanggan yang pemakaian air boros, sedang dan hemat.

Ong Johan Oscar (2013) dengan penelitiannya yang mengangkat judul "Implementasi Algoritma KMeans Clustering Untuk Menentukan Strategi Marketing President University". Tujuan penulisan yang dijelaskan penulis dalam makalah ini menunjukkan bahwa hasil dari pengolahan data mahasiswa membantu pihak marketing President Unversity dalam melakukan pemasaran dan mencari calon mahasiswa baru dari berbagai kota di Indonesia. Dan hasilnya cukup efisien dan efektif

Ari Muzakir (2014) yang dalam penelitiannya berjudul "Analisa Dan Pemanfaatan Algoritma $K$ Means Clustering Pada Data Nilai Siswa Sebagi Penentuan Penerima Beasiswa" dengan hasil Algoritma K-Means dapat melakukan pengelompokan dokumen dalam jumlah yang banyak dalam penentuan penerima beasiswa.

Rahayu Mayang Sari (2015) dalam penelitiannya yang berjudul "Prediksi Data Anggaran Pendapatan Belanja Daerah Menggunakan Algoritma K-Means" dengan hasil penelitian Sistem clustering data Anggaran Pendapatan Belanja Daerah (APBD) 
menggunakan algoritma K-Means dapat mengelompokan dan memprediksi data pada tahun berikutnya

Berdasarkan uraian diatas, penulis berencana membuat tesis dalam pembagian kelompok bimbingan belajar berdasarkan tingkat kemampuan siswa. Pembagian kelompok dibantu oleh perangkat lunak hasil implementasi dari metode clustering yang dapat mengelompokkan siswa belajar dengan valid. Dengan adanya pembagian kelompok ini diharapkan dapat membantu para siswa untuk lebih cepat memahami dan menguasai mata pelajaran yang dibimbingkan.

\subsection{Perumusan Masalah}

Berdasarkan uraian latar belakang yang ada maka dirumuskan pokok permasalahannya adalah :

1. Bagaimana cara menentukan kelompok kelas belajar tambahan materi mata pelajaran dengan metode $K$-Means?

2. Bagaimana cara menerapkan Data Mining dengan metode $K$-Means?

3. Bagaimana cara menguji metode $K$-Means ke dalam Software Rapid Miner Studio Versi 7.3 ?

1.3

\section{Batasan Masalah}

Agar penelitian ini terarah kepada pokok permasalahan, maka penulis membatasi masalah penelitian ini sebagai berikut :

1. Metode yang digunakan dalam penyelesaian masalah ini adalah metode $K$-Means.

2. Data yang digunakan adalah data nilai ujian semester kelas XII jurusan IPA.

3. Menggunakan Software Rapid Minner Studio Versi 7.3 dalam pengujian data.

\subsection{Tujuan Penelitian}

Dalam penelitian ini, penulis memiliki beberapa tujuan yang ingin dicapai, tujuan tersebut yaitu :

1. Agar guru dapat membagi kelompok secara efektif untuk memberi materi belajar tambahan terhadap siswa.

2. Agar peneliti dapat mengetahui cara kerja Algoritma K-Means.

3. Menerapkan Software Rapid Minner Studio Versi 7.3 untuk menguji metode $K$-Means.

\subsection{Manfaat Penelitian}

Selain memiliki tujuan, penelitian ini juga diharapkan dapat memberikan manfaat bagi berbagai pihak yang nantinya akan menggunakan $K$-Means ini. Adapun manfaat penelitian ini antara lain :

1. Memberikan suatu pengetahuan dalam menentukan kelompok belajar tambahan mata pelajaran.

2. Diharapkan dengan menggunakan metode ini pihak sekolah terbantu dalam menentukan kelompok belajar tambahan secara efektif.

\section{LANDASAN TEORI}

\subsection{Knowledge Discoveryin Database (KDD)}

Knowledge discovery in database (KDD) adalah kegiatan yang meliputi pengumpulan, pemakaian data historis untuk menemukan keteraturan pola atau hubungan dalam set data berukuran besar (Buulolo, 2013).

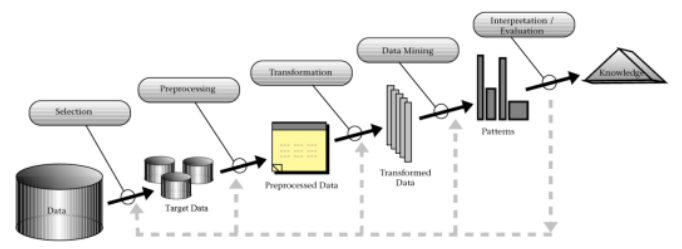

Gambar 2.1 Aliran Informasi Dalam Data Mining

\subsection{Data Mining}

Menurut Widodo (2013) Data Mining adalah analisa terhadap data untuk menemukan hubungan yang jelas serta menyimpulkannya yang belum diketahui sebelumnya dengan cara terkini dipahami dan berguna bagi pemilik data tersebut.

\subsection{Clustering}

Menurut Widodo (2013) Clustering atau klasifikasi adalah metode yang digunakan untuk membagi rangkaian data menjadi beberapa group berdasarkan kesamaan-kesamaan yang telah ditentukan sebelumnya. 


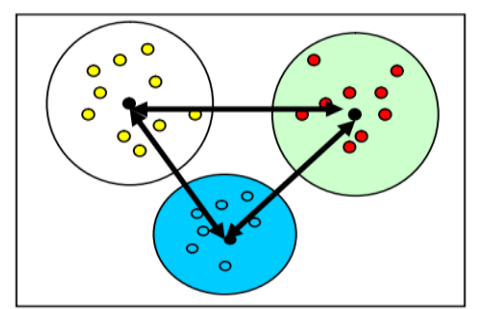

Gambar 2.2 Clustering
6. Melakukan perulangan dari langkah 2 hingga 5,sampai anggota tiap cluster tidak ada yang berubah.

Jika langkah 6 telah terpenuhi, maka nilai pusa cluster $(\mu j)$ pada iterasi terakhir akan digunakan sebagai parameter untuk menentukan klasifikasi data.

\subsection{Algoritma K-Means}

Menurut Eko Prasetyo (2012) mengatakan bahwa metode K-Means ini mempartisi data kedalam kelompok sehingga data berkarakteristik sama dimasukan kedalam sat kelompok yang sama dan data yang berkarakteristik berbeda dikelompokkan kedalam kelompok yang lain.

Langkah-langkah melakukan clustering dengan metode $K$-Means adalah sebagai berikut:

1. Tentukan nilai $k$ sebagai jumlah klaster yang ingin dibentuk.

2. Inisialisasi $k$ pusat cluster ini bisa dilakukan dengan berbagai cara, namun yang paling sering dilakukan adalah dengan cara random yang di ambil dari data yang ada.

3. Menghitung jarak setiap data input terhadap masing - masing centroid menggunakan rumus jarak Euclidean (Euclidean Distance) hingga ditemukan jarak yang paling dekat dari setiap data dengan centroid. Berikut adalah persamaan Euclidian Distance :

$$
d(x i, \mu j)=\sqrt{\sum(x i-\mu j)^{2}}-(\mathbf{2 . 1})
$$

Dimana :

$$
\begin{aligned}
& d: \text { titik dokumen } \\
& x i: \text { data kriteria } \\
& \mu j: \text { centroid pada cluster ke-j }
\end{aligned}
$$

4. Mengklasifikasikan setiap data berdasarkan kedekatannya dengan centroid (jarak terkecil).

5. Memperbaharui nilai centroid. Nilai centroid baru di peroleh dari rata-rata cluster yang bersangkutan dengan menggunakan rumus: $\mu j(t+1)=\frac{1}{N s j} \sum_{j \in s j} x j$

\section{Dimana:}

$\mu \mathrm{j}(\mathrm{t}+1)$ : centroid baru pada iterasi ke $(\mathrm{t}+1)$

Nsj : banyak data pada cluster sj,

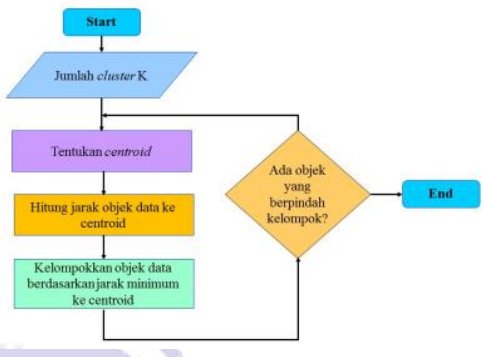

Gambar 2.3 Flowchart Algoritma K-Means Clustering

\section{ANALISA DAN PERANCANGAN}

\subsection{Analisa Sistem}

Tahap analisa sistem merupakan tahap yang paling penting karena pada tahap ini akan dilakukan evaluasi kinerja, identifikasi terhadap masalah dan cara kerja sistem. Analisa system bertujuan untuk mengetahui semua pengetahuan yang berkaitan dengan data nilai mata pelajaran Ujian Nasional.

SMA Negeri 1 Ranah Pesisir dalam menghadapi Ujian Nasional (UN) akan mengadakan suatu belajar tambahan, hal ini bertujuan untuk memantapkan materi-materi mata pelajaran yang akan di ujikan, maka pihak sekolah harus memberikan belajar tambahan kepada siswa yang kemampuannya rendah karena syarat untuk lulus dalam ujian nasional ini semua mata pelajaran yang diujikan harus memenuhi nilai standar lulus yang telah ditentukan jika salah satu mata pelajaran ujian nasional tidak lulus maka dinyatakan siswa tersebut tidak lulus dalam ujian nasional.

\subsection{Pengumpulan Data}

Pada proses pengumpulan data ada enam parameter yang akan digunakan dalam pengolahan data yaitu nilai mata pelajaran Ujian Nasional SMA Jurusan IPA. Ujian Nasional adalah sistem standar pendidikan dasar dan menengah yang dilakukan secara nasional sesuai keputusan menteri pendidikan dan berdasarkan UU nomor 20 tahun 2003. Pada penelitian ini data yang dikumpulkan yaitu data nilai Ujian Nasional SMA jurusan IPA yang meliputi data nilai bahasa indonesia, bahasa inggris, matematika, fisika, biologi, dan kimia Data tersebut diambil dari SMA Negeri 1 Ranah Pesisir, dengan jumlah keseluruhan data 166 record. 
Proceding SEMILOKA ROYAL 2017 “Teknologi Mobile” 02 Desember 2017 Hal-105

\begin{tabular}{|c|c|c|c|c|c|c|c|}
\hline No & NAMA & BI & BING & MTK & FIS & BIO & KIM \\
\hline 1 & $\begin{array}{l}\text { ANGGI } \\
\text { MALDO } \\
\text { JEFRA }\end{array}$ & 89 & 88 & 80 & 81 & 83 & 80 \\
\hline 2 & $\begin{array}{l}\text { DIO } \\
\text { HARVANDY }\end{array}$ & 86 & 80 & 78 & 87 & 81 & 82 \\
\hline 3 & $\begin{array}{l}\text { ELDERA } \\
\text { RIZKI } \\
\text { NURAINI }\end{array}$ & 85 & 83 & 80 & 77 & 70 & 80 \\
\hline 4 & $\begin{array}{l}\text { ERGA } \\
\text { SHINTA } \\
\text { ANGELA }\end{array}$ & 80 & 80 & 82 & 80 & 75 & 81 \\
\hline 5 & $\begin{array}{l}\text { ERIK } \\
\text { KRISMON } \\
\text { EFENDI }\end{array}$ & 84 & 79 & 80 & 84 & 82 & 85 \\
\hline 6 & $\begin{array}{l}\text { EXSIS } \\
\text { YUPITA SARI }\end{array}$ & 86 & 78 & 80 & 78 & 83 & 80 \\
\hline 7 & $\begin{array}{l}\text { FEBI } \\
\text { KEMBARA } \\
\text { PUTRA }\end{array}$ & 88 & 87 & 85 & 87 & 81 & 85 \\
\hline 8 & $\begin{array}{l}\text { IBNU } \\
\text { MUHAMMAD } \\
\text { IKHSAN }\end{array}$ & 80 & 80 & 80 & 80 & 81 & 78 \\
\hline 9 & $\begin{array}{l}\text { ICE } \\
\text { MAIDIKA } \\
\text { SARI }\end{array}$ & 84 & 87 & 80 & 81 & 79 & 80 \\
\hline 10 & $\begin{array}{l}\text { IFNI } \\
\text { SUKANTI }\end{array}$ & 84 & 80 & 80 & 81 & 82 & 80 \\
\hline 11 & $\begin{array}{l}\text { ILHAM } \\
\text { RINALDO } \\
\text { PUTRA }\end{array}$ & 86 & 84 & 80 & 83 & 75 & 80 \\
\hline 12 & $\begin{array}{l}\text { ILHAM } \\
\text { YULIANDRA }\end{array}$ & 86 & 84 & 85 & 80 & 83 & 81 \\
\hline 13 & $\begin{array}{l}\text { LAILATUL } \\
\text { WARAHMAH }\end{array}$ & 84 & 80 & 84 & 81 & 79 & 81 \\
\hline 14 & $\begin{array}{l}\text { MEIDI } \\
\text { KRISTIAN }\end{array}$ & 83 & 89 & 80 & 80 & 83 & 79 \\
\hline 15 & $\begin{array}{l}\text { MELLA } \\
\text { ELVIANA }\end{array}$ & 86 & 89 & 87 & 82 & 85 & 78 \\
\hline 16 & $\begin{array}{l}\text { MITA } \\
\text { TRISNAWATI }\end{array}$ & 89 & 85 & 80 & 78 & 82 & 81 \\
\hline 17 & $\begin{array}{l}\text { NURANI } \\
\text { AULIA PUTRI }\end{array}$ & 75 & 85 & 79 & 80 & 82 & 79 \\
\hline 18 & $\begin{array}{l}\text { PANZHER } \\
\text { PUTRA }\end{array}$ & 90 & 84 & 98 & 80 & 95 & 90 \\
\hline 19 & $\begin{array}{l}\text { RANDI } \\
\text { ZONNANDA } \\
\text { PUTRA }\end{array}$ & 91 & 83 & 78 & 87 & 85 & 81 \\
\hline 20 & $\begin{array}{l}\text { REZA SURYA } \\
\text { PUTRI }\end{array}$ & 75 & 89 & 80 & 80 & 85 & 90 \\
\hline 21 & RICE PRIANI & 90 & 82 & 80 & 81 & 81 & 79 \\
\hline 22 & $\begin{array}{l}\text { SATRIA } \\
\text { BUANA }\end{array}$ & 80 & 79 & 79 & 83 & 81 & 80 \\
\hline 23 & $\begin{array}{l}\text { SHERLY } \\
\text { WULANDARI }\end{array}$ & 75 & 87 & 80 & 79 & 83 & 79 \\
\hline 24 & SILVIA & 80 & 90 & 70 & 80 & 78 & 91 \\
\hline 25 & SISKA & 90 & 86 & 80 & 86 & 84 & 80 \\
\hline 26 & $\begin{array}{l}\text { SUCI NUR } \\
\text { INDAH SARI }\end{array}$ & 95 & 90 & 92 & 90 & 96 & 90 \\
\hline
\end{tabular}

Sumber : Nilai UAS Semester IV SMAN 1 Ranah Pesisir Jurusan IPA

Data diatas merupakan sampel data nilai UAS Semester IV SMAN 1 Ranah Pesisir jurusan IPA berjumlah 26 record, data tersebut akan dikluster menjadi tiga kelompok yaitu kemampuan siswa pintar, siswa sedang dan siswa kurang pintar.

\subsection{Proses Clustering Menggunakan Algoritma K-Means}

Data yang sudah dijadikan sampel akan dilakukan pengolahan data dengan proses clustering dengan menggunakan algoritma K-Means sehingga didapatkanlah hasil pengelompokan data yang diinginkan. Adapun langkah dalam cluster dengan algoritma K-Means yaitu :

1. Menentukan Jumlah Cluster

Menentukan jumlah cluster yang digunakan pada data nilai ujian SMAN 1 Ranah Pesisir sebanyak 3 cluster diantaranya pintar, sedang dan kurang pintar berdasarkan mata pelajaran ujian nasional jurusan IPA.

2. Menentukan Centroid

Penentuan pusat awal cluster (centroid) ditentukan secara random atau acak yang diambil dari data yang ada. Nilai cluster 0 diambil dari baris ke-26, nilai cluster 1 pada baris ke-10, nilai cluster 2 pada baris ke-20.

\section{Centroid Awal}

\begin{tabular}{|l|l|l|l|l|l|l|}
\hline CLUSTER & BI & BING & MTK & FIS & BIO & KIM \\
\hline C0 & 95 & 90 & 92 & 90 & 96 & 90 \\
\hline C1 & 84 & 80 & 80 & 81 & 82 & 80 \\
\hline C2 & 75 & 89 & 80 & 80 & 85 & 90 \\
\hline
\end{tabular}

3. Menghitung Jarak dari Centroid Menghitung jarak antara titik centroid dengan titik tiap objek dengan menggunakan Euclidian Distance. Adapun penghitungan centroid awal secara manual. Perhitungannya adalah sebagai berikut :

$\mathrm{D}(i, f)=\sqrt{\left(\mathrm{X}_{\mathrm{i} 1}-\mathrm{X}_{1 \mathrm{j}}\right)^{2}+\left(\mathrm{X}_{2 \mathrm{i}}-\mathrm{X}_{2 \mathrm{j}}\right)^{2}+\ldots+\left(\mathrm{X}_{\mathrm{ki}}-\mathrm{X}_{\mathrm{kj}}\right)^{2}}$ (4.1)

Tabel Perhitungan Jarak dan Pengelompokan Data Iterasi Ke-1

\begin{tabular}{|c|c|c|c|c|c|c|c|}
\hline NO & NIS & $\mathrm{DC} 0$ & DC1 & $\mathrm{DC} 2$ & $\mathrm{C} 0$ & $\mathrm{C} 1$ & $\mathrm{C} 2$ \\
\hline 1 & 14137 & 23.11 & 9.49 & 17.38 & 0 & 1 & 0 \\
\hline 2 & 14138 & 25.98 & 7.00 & 18.30 & 0 & 1 & 0 \\
\hline 3 & 14139 & 35.19 & 13.04 & 21.68 & 0 & 1 & 0 \\
\hline 4 & 14140 & 32.36 & 8.43 & 17.06 & 0 & 1 & 0 \\
\hline 5 & 14141 & 25.36 & 5.92 & 15.20 & 0 & 1 & 0 \\
\hline 6 & 14142 & 27.96 & 4.24 & 18.71 & 0 & 1 & 0 \\
\hline 7 & 14143 & 19.13 & 12.33 & 16.97 & 0 & 1 & 0 \\
\hline 8 & 14144 & 30.63 & 4.69 & 16.31 & 0 & 1 & 0 \\
\hline 9 & 14145 & 27.28 & 7.62 & 14.90 & 0 & 1 & 0 \\
\hline 10 & 14146 & 27.24 & 0.00 & 16.49 & 0 & 1 & 0 \\
\hline 11 & 14147 & 29.17 & 8.54 & 18.84 & 0 & 1 & 0 \\
\hline 12 & 14148 & 22.72 & 6.93 & 16.00 & 0 & 1 & 0 \\
\hline 13 & 14149 & 27.13 & 5.10 & 17.20 & 0 & 1 & 0 \\
\hline 14 & 14150 & 26.06 & 9.22 & 13.75 & 0 & 1 & 0 \\
\hline 15 & 14151 & 20.88 & 12.17 & 17.83 & 0 & 1 & 0 \\
\hline 16 & 14152 & 25.02 & 7.75 & 17.49 & 0 & 1 & 0 \\
\hline 17 & 14153 & 31.80 & 10.44 & 12.12 & 0 & 1 & 0 \\
\hline 18 & 14154 & 14.07 & 25.42 & 25.96 & 1 & 0 & 0 \\
\hline 19 & 14155 & 21.73 & 10.39 & 20.64 & 0 & 1 & 0 \\
\hline 20 & 14156 & 27.68 & 16.49 & 0.00 & 0 & 0 & 1 \\
\hline 21 & 14157 & 25.69 & 6.48 & 20.30 & 0 & 1 & 0 \\
\hline
\end{tabular}


Proceding SEMILOKA ROYAL 2017 “Teknologi Mobile” 02 Desember 2017 Hal-105

\begin{tabular}{|l|l|l|l|l|l|l|l|}
\hline 22 & 14158 & 29.82 & 4.80 & 15.84 & 0 & 1 & 0 \\
\hline 23 & 14159 & 31.05 & 11.66 & 11.40 & 0 & 0 & 1 \\
\hline 24 & 14160 & 33.67 & 18.81 & 13.27 & 0 & 0 & 1 \\
\hline 25 & 14161 & 21.10 & 10.05 & 19.26 & 0 & 1 & 0 \\
\hline 26 & 14162 & 0.00 & 27.24 & 27.68 & 1 & 0 & 0 \\
\hline
\end{tabular}

Dari hasil perhitungan di atas didapatkan pusat cluster baru seperti Tabel sebagai berikut :

\section{Tabel Centroid Baru Iterasi Ke-1}

\begin{tabular}{|c|c|c|c|c|c|c|}
\hline CLUSTER & BI & BING & MTK & FIS & BIO & KIM \\
\hline C0 & 92.50 & 87.00 & 95.00 & 85.00 & 95.50 & 90.00 \\
\hline C1 & 85.05 & 83.24 & 80.81 & 81.76 & 80.81 & 80.48 \\
\hline C2 & 76.67 & 88.67 & 76.67 & 79.67 & 82.00 & 86.67 \\
\hline
\end{tabular}

6. Iterasi selanjutnya melakukan perhitungan lagi dengan menggunakan titik centroid yang baru Iterasi Ke-1.

Tabel Perhitungan Jarak dan Pengelompokan Data Iterasi Ke-2

\begin{tabular}{|c|c|c|c|c|c|c|c|}
\hline NO & NIS & DC0 & DC1 & DC2 & C0 & C1 & C2 \\
\hline 1 & 14137 & 22.59 & 6.67 & 14.52 & 0 & 1 & 0 \\
\hline 2 & 14138 & 25.66 & 7.01 & 15.51 & 0 & 1 & 0 \\
\hline 3 & 14139 & 33.34 & 11.85 & 17.56 & 0 & 1 & 0 \\
\hline 4 & 14140 & 30.01 & 8.63 & 14.00 & 0 & 1 & 0 \\
\hline 5 & 14141 & 23.86 & 6.83 & 13.41 & 0 & 1 & 0 \\
\hline 6 & 14142 & 25.56 & 6.94 & 16.13 & 0 & 1 & 0 \\
\hline 7 & 14143 & 18.96 & 9.40 & 16.06 & 0 & 1 & 0 \\
\hline 8 & 14144 & 28.45 & 6.78 & 13.18 & 0 & 1 & 0 \\
\hline 9 & 14145 & 26.18 & 4.47 & 11.08 & 0 & 1 & 0 \\
\hline 10 & 14146 & 25.39 & 3.81 & 13.65 & 0 & 1 & 0 \\
\hline 11 & 14147 & 28.29 & 6.14 & 14.98 & 0 & 1 & 0 \\
\hline 12 & 14148 & 20.33 & 5.22 & 14.54 & 0 & 1 & 0 \\
\hline 13 & 14149 & 24.73 & 5.09 & 15.02 & 0 & 1 & 0 \\
\hline 14 & 14150 & 24.93 & 6.94 & 10.55 & 0 & 1 & 0 \\
\hline 15 & 14151 & 19.33 & 9.81 & 16.84 & 0 & 1 & 0 \\
\hline 16 & 14152 & 23.53 & 5.93 & 14.54 & 0 & 1 & 0 \\
\hline 17 & 14153 & 29.91 & 8.98 & 10.68 & 0 & 1 & 0 \\
\hline 18 & 14154 & 7.04 & 24.81 & 28.89 & 1 & 0 & 0 \\
\hline 19 & 14155 & 22.42 & 9.41 & 18.28 & 0 & 1 & 0 \\
\hline 20 & 14156 & 25.89 & 15.69 & 5.85 & 0 & 0 & 1 \\
\hline 21 & 14157 & 24.57 & 5.43 & 17.17 & 0 & 1 & 0 \\
\hline 22 & 14158 & 28.12 & 6.97 & 12.91 & 0 & 1 & 0 \\
\hline
\end{tabular}

\begin{tabular}{|l|l|l|l|l|l|l|l|}
\hline 23 & 14159 & 29.06 & 8.77 & 11.42 & 0 & 1 & 0 \\
\hline 24 & 14160 & 33.50 & 17.60 & 9.60 & 0 & 0 & 1 \\
\hline 25 & 14161 & 21.58 & 7.82 & 16.87 & 0 & 1 & 0 \\
\hline 26 & 14162 & 7.04 & 25.67 & 29.78 & 1 & 0 & 0 \\
\hline
\end{tabular}

Dari centroid baru iterasi ke-2, dilakukan perhitungan kembali, sehingga di dapatkan hasil Tabel Perhitungan Jarak dan Pengelompokan Data Iterasi Ke-1 dimana C0 memiliki 2 anggota, $\mathrm{C} 1$ memiliki 22 anggota, C2 memiliki 2 anggota.

Berdasarkan dari perhitungan di atas bahwa pusat cluster baru iterasi ke-1 seperti Tabel sebagai berikut :

\section{Tabel Centroid Baru Iterasi Ke-2}

\begin{tabular}{|l|l|l|l|l|l|l|}
\hline CLUSTER & BI & BING & MTK & FIS & BIO & KIM \\
\hline C0 & 92.50 & 87.00 & 95.00 & 85.00 & 95.50 & 90.00 \\
\hline C1 & 85.55 & 83.15 & 80.90 & 81.85 & 80.75 & 80.55 \\
\hline C2 & 76.25 & 87.75 & 77.25 & 79.75 & 82.00 & 84.75 \\
\hline
\end{tabular}

Dari hasil centroid yang didapatkan pada iterasi ke-2,kemudian lakukan lagi perhitungan yang sama sampai anggota tiap cluster tidak ada lagi yang berubah.

Tabel Perhitungan Jarak dan Pengelompokan Data Iterasi Ke-3

\begin{tabular}{|c|c|c|c|c|c|c|c|}
\hline NO & NIS & DCO & DC1 & DC2 & CO & C1 & C2 \\
\hline 1 & 14137 & 22.59 & 6.51 & 13.98 & 0 & 1 & 0 \\
\hline 2 & 14138 & 25.66 & 6.87 & 14.72 & 0 & 1 & 0 \\
\hline 3 & 14139 & 33.34 & 11.85 & 16.76 & 0 & 1 & 0 \\
\hline 4 & 14140 & 30.01 & 8.87 & 12.64 & 0 & 1 & 0 \\
\hline 5 & 14141 & 23.86 & 6.81 & 12.74 & 0 & 1 & 0 \\
\hline 6 & 14142 & 25.56 & 6.91 & 14.98 & 0 & 1 & 0 \\
\hline 7 & 14143 & 18.96 & 9.17 & 15.88 & 0 & 1 & 0 \\
\hline 8 & 14144 & 28.45 & 7.18 & 11.33 & 0 & 1 & 0 \\
\hline 9 & 14145 & 26.18 & 4.70 & 10.07 & 0 & 1 & 0 \\
\hline 10 & 14146 & 25.39 & 3.97 & 12.32 & 0 & 1 & 0 \\
\hline 11 & 14147 & 28.29 & 6.04 & 14.10 & 0 & 1 & 0 \\
\hline 12 & 14148 & 20.33 & 5.14 & 13.58 & 0 & 1 & 0 \\
\hline 13 & 14149 & 24.73 & 5.09 & 13.80 & 0 & 1 & 0 \\
\hline 14 & 14150 & 24.93 & 7.24 & 9.42 & 0 & 1 & 0 \\
\hline 15 & 14151 & 19.33 & 9.81 & 15.85 & 0 & 1 & 0 \\
\hline 16 & 14152 & 23.53 & 5.72 & 13.96 & 0 & 1 & 0 \\
\hline
\end{tabular}




\begin{tabular}{|c|c|c|c|c|c|c|l|}
\hline 17 & 14153 & 29.91 & 6.73 & 11.21 & 0 & 1 & 0 \\
\hline 18 & 14154 & 7.04 & 24.67 & 28.82 & 1 & 0 & 0 \\
\hline 19 & 14155 & 22.42 & 9.11 & 17.79 & 0 & 1 & 0 \\
\hline 20 & 14156 & 25.89 & 16.04 & 6.88 & 0 & 0 & 1 \\
\hline 21 & 14157 & 24.57 & 5.01 & 16.29 & 0 & 1 & 0 \\
\hline 22 & 14158 & 28.12 & 7.30 & 11.31 & 0 & 1 & 0 \\
\hline 23 & 14159 & 29.06 & 6.66 & 11.94 & 0 & 1 & 0 \\
\hline 24 & 14160 & 33.50 & 17.80 & 11.26 & 0 & 0 & 1 \\
\hline 25 & 14161 & 21.58 & 7.54 & 16.29 & 0 & 1 & 0 \\
\hline 26 & 14162 & 7.04 & 25.45 & 30.05 & 1 & 0 & 0 \\
\hline
\end{tabular}

Tabel Centroid Baru Iterasi Ke-3

\begin{tabular}{|c|c|c|c|c|c|c|}
\hline CLUSTER & BI & BING & MTK & FIS & BIO & KIM \\
\hline C0 & 92.50 & 87.00 & 95.00 & 85.00 & 95.50 & 90.00 \\
\hline C1 & 85.55 & 83.15 & 80.90 & 81.85 & 80.75 & 80.55 \\
\hline C2 & 76.25 & 87.75 & 77.25 & 79.75 & 82.00 & 84.75 \\
\hline
\end{tabular}

Karena pada Iterasi Ke-2 dan Ke-3 posisi cluster tidak berubah maka iterasi dihentikan dan hasil akhir yang diperoleh yaitu ;

1. Co memiliki 2 anggota yang diartikan bahwa kelompok pertama adalah kategori kemampuan siswa pintar.

2. C1 memiliki 22 anggota yang diartikan bahwa kelompok kedua adalah kategori kemampuan siswa sedang.

3. C2 memiliki 2 anggota yang diartikan bahwa kelompok ketiga adalah kategori kemampuan siswa kurang pintar dan siswa inilah yang akan diberi belajar tambahan.

\section{KESIMPULAN DAN SARAN}

\subsection{Kesimpulan}

Berdasarkan uraian yang sudah dikemukakan pada bab-bab sebelumnya, maka dapat ditarik beberapa kesimpulan sebagai berikut :

1. Metode Clustering dengan algoritma K-Means dapat digunakan untuk mengelompokkan data siswa berdasarkan nilai ujian semester mata pelajaran Ujian Nasional, yaitu kemampuan siswa pintar, siswa sedang dan siswa kurang pintar. sehingga dapat mengetahui siswa yang mana saja yang akan diberi belajar tambahan agar dapat mencapai nilai standar kelulusan Ujian Nasional.

2. Metode Clustering dapat digunakan untuk membantu pihak sekolah untuk melakukan belajar tambahan terhadap siswa yang akan mengikuti Ujian Nasional.

\subsection{Saran}

Penulis menyadari adanya kekurangan dalam penulisan ini, karena keterbatasan penulis baik dalam hal waktu maupun pengetahuan. Dalam rangka memperbaiki kekurangan dan untuk penyempurnaan penelitian ini penulis memberikan beberapa saran sebagai berikut :

1. Untuk penelitian selanjutnya dapat dilakukan dengan data yang lebih banyak dan parameter yang lebih banyak lagi.

2. Untuk memaksimalkan waktu proses clustering dengan algoritma K-Means, penentuan centroid awal yang baik akan membuat proses clustering dapat dilakukan dengan lebih cepat.

Untuk penelitian selanjutnya dalam hal pengektrasian data nilai siswa matapelajaran Ujian Nasional bisa menerapkan metode Data Mining dengan algoritma yang berbeda.

\section{DAFTAR PUSTAKA}

Sri Tria Siska (2016). “Analisa Penerapan Data Mining Untuk Menenyukan Kubikasi Air Terjual Berdasarkan Pengelompokan Pelanggan Menggunakan Algoritma K-Means Clustering”. Vol. 9. 1 April 2016, ISSN : 2086-4981

Bendri Melpa Metisen dan Herlina Latipa Sari (2015). "Analisis Clustering Menggunakan Metode KMeans Dalam Pengelompokkan Penjualan Produk Pada Swalayan Fadhila". Vol. 11 No. 2, September 2015, ISSN : 1858 - 2680.

Asroni dan Ronald Adrian (2015). "Penerapan Metode K-Means Untuk Clustering Mahasiswa Berdasarkan Nilai Akademik Dengan Weka Interfase Studi Kasus Pada Jurusan Teknik Informasi UMM Magelang”. Vol. 18, No. 1, 7682, Mei 2015.

Nurul Romawati W, et al (2015). "Implementasi Algoritma K-means Dalam Pengklasteran Mahasiswa Pelamar Beasiswa". Vol. 01, No. 2, 30 April 2015, ISSN : 2407-3911

Fina Nasari dan Surya Darma (2015). "Penerapan KMeans Clustering Pada Data Penerimaan Mahasiswa Baru". ISSN : 2302-3805 